\title{
SATISFAÇÃO E INSATISFAÇÃO DE RESIDENTES MULTIPROFISSIONAIS EM SAÚDE NA PERSPECTIVA DA FORMAÇÃO
}

\author{
SATISFACTION AND DISSATISFACTION OF \\ MULTIPROFESSIONAL RESIDENTS IN HEALTH IN THE \\ PERSPECTIVE OF PROFESSIONAL TRAINING
}

\section{SATISFACCIÓN E INSATISFACCIÓN DE RESIDENTES MULTIPROFESIONALES EN SALUD EN LA PERSPECTIVA DE SU FORMACIÓN}

\author{
Marcelo Nunes da Silva Fernandes ${ }^{1}$ \\ Carmem Lúcia Colomé Beck ${ }^{2}$ \\ Teresinha Heck Weiller ${ }^{3}$ \\ Alexa Pupiara Flores Coelho ${ }^{4}$ \\ Francine Cassol Prestes ${ }^{4}$ \\ Daiany Saldanha da Silveira Donaduzzi ${ }^{5}$
}

Como citar este artigo: Fernandes MNS, Beck CLC, Weiller TH, Coelho APF, Prestes FC, Donaduzzi DSS. Satisfação e insatisfação de residentes multiprofissionais em saúde na perspectiva da formação. Rev baiana enferm. 2017;31(3):e18344.

Objetivo: descrever as vivências de satisfação e insatisfação de residentes multiprofissionais em saúde na perspectiva da formação. Método: pesquisa qualitativa, realizada com nove residentes de um Programa de Residência Multiprofissional em Saúde de uma universidade pública do Sul do Brasil. Os dados, produzidos por meio de grupo focal realizado em abril de 2013, foram submetidos à análise de conteúdo na modalidade temática. Resultados: os residentes possuíam vivências de satisfação relacionadas ao compartilhamento de conhecimentos e gratificação do usuário. As vivências de insatisfação davam-se pela falta de comunicação na equipe, sobrecarga de trabalho, extensa carga horária, dificuldade na articulação da teoria com a prática e demandas impostas. Conclusão: os participantes vivenciavam sentimentos opostos, apesar de o processo de formação dos residentes conferir-lhes satisfação, o que indica a necessidade de diálogo e sensibilização das instituições formadoras.

Descritores: Desenvolvimento de pessoal. Satisfação no emprego. Internato não médico. Enfermagem. Pesquisa qualitativa.

\footnotetext{
Enfermeiro. Mestre em Enfermagem. Especialista em Saúde Coletiva e Gestão de Organização Pública em Saúde. Enfermeiro da Prefeitura Municipal de Santa Maria. Santa Maria, Rio Grande do Sul, Brasil.

2 Enfermeira. Doutora em Filosofia da Enfermagem. Professora Adjunta do Departamento de Enfermagem e do Programa de Pós-graduação em Enfermagem da Universidade Federal de Santa Maria. Santa Maria, Rio Grande do Sul, Brasil.

Enfermeira. Doutora em Enfermagem em Saúde Pública. Professora Adjunta do Departamento de Enfermagem e do Programa de Pós-graduação em Enfermagem da Universidade Federal de Santa Maria. Santa Maria, Rio Grande do Sul, Brasil.

Enfermeiras. Doutorandas do Programa de Pós-graduação em Enfermagem da Universidade Federal de Santa Maria. Santa Maria, Rio Grande do Sul, Brasil. alexa.p.coelho@hotmail.com

5 Enfermeira. Mestre em Enfermagem. Especialista em Saúde Pública e Saúde Coletiva. Docente do Curso de Enfermagem da Faculdade Integrada de Santa Maria. Enfermeira da Prefeitura Municipal de Santa Maria. Santa Maria, Rio Grande do Sul, Brasil.
} 
Objective: to describe the experiences of satisfaction and dissatisfaction of multiprofessional residents in health in the perspective of their professional training. Method: a qualitative study was performed with nine residents of a Multiprofessional Residency Program in Health from a public university in the south of Brazil. The data obtained through a focus group in April 2013 were submitted to thematic content analysis. Results: the residents had experiences of satisfaction associated with knowledge sharing and user gratification. Experiences of dissatisfaction resulted from the team's lack of communication, work overload, excessive working bours, difficulty linking theory to practice, and imposed demands. Conclusion: although the professional qualification process provided by the residency course, the participants experienced opposing feelings; which indicates the need for qualifying institutions to promote dialogue and raise awareness.

Descriptors: Staff development. Job satisfaction. Internship, non-medical. Nursing. Qualitative research.

Objetivo: describir las vivencias de satisfacción e insatisfacción de los residentes multiprofesionales en salud en la perspectiva de su formación. Método: investigación de enfoque cualitativo, realizada con nueve residentes de un Programa de Residencia Multiprofesional en Salud de una universidad pública del Sur de Brasil. Los datos, obtenidos a través de un grupo focal, realizado en abril de 2013, fueron sometidos al análisis de contenido en la modalidad temática. Resultados: los residentes poseían vivencias de satisfacción relacionadas a los conocimientos compartidos y a la gratificación del usuario. Las vivencias de insatisfacción se debian a la falta de comunicación en el equipo, la sobrecarga de trabajo, una extensa carga horaria, la dificultad en la articulación entre la teoría y la práctica y, a demandas impuestas. Conclusión: los participantes vivenciaban sentimientos opuestos, a pesar de que el proceso de formación de los residentes les confería satisfacción, lo que indica la necesidad de diálogo y sensibilización de las instituciones formadoras.

Descriptores: Desarrollo de personal. Satisfacción en el trabajo. Internado no médico. Enfermería. Investigación cualitativa.

\section{Introdução}

A Política Nacional de Educação Permanente em Saúde (PNEPS) foi criada em 2004 como estratégia para a formação e o desenvolvimento de trabalhadores para o setor da saúde e, em especial, para o Sistema Único de Saúde (SUS) ${ }^{(1)}$. Nessa perspectiva, inserem-se no âmbito do Ministério da Saúde e da Educação as Residências Multiprofissionais em Saúde (RMS), por meio da Portaria Interministerial n. $2.117 / 2005^{(2)}$. No ano de 2007, a Portaria Interministerial n. 45 reconheceu essa modalidade de formação em saúde como curso de especialização caracterizado por ensino em serviço, no nível de pós-graduação lato sensu ${ }^{(3)}$.

Os Programas de RMS representam uma das estratégias para repensar o processo de formação por meio da integração de práticas e saberes das profissões envolvidas. Além disso, buscam a qualificação da atenção e do processo de trabalho das equipes, bem como a integração ensino-serviço. Assim, esses programas representam um instrumento potencializador da formação e da qualificação de trabalhadores para o SUS ${ }^{(4)}$.
Somado a isso, a característica da interdisciplinaridade confere caráter inovador aos programas, por meio de um processo de formação coletivo inserido no mesmo campo de atuação, com respeito aos núcleos específicos de conhecimento de cada profissão.

Dada a centralidade do papel do residente nesse processo, é importante considerar suas percepções enquanto sujeito implicado no processo de formação. As vivências de satisfação e insatisfação estão imbricadas nas relações que os trabalhadores estabelecem com seus núcleos de trabalho. O residente, apesar de estar em um momento formativo, experimenta o trabalho em saúde por meio da aplicação de suas competências profissionais. Portanto, vivências de satisfação e insatisfação são sentimentos que permeiam seu cotidiano de trabalho, podendo interferir em sua saúde psíquica.

O conceito de satisfação no trabalho é explorado por diferentes áreas do conhecimento, como psicologia, sociologia, administração, dentre outras. Esse conceito é complexo, na 
medida em que existe uma vasta gama de definições. No entanto, a maior parte da literatura indica que os trabalhadores possuem necessidades individuais e a satisfação no trabalho está relacionada ao grau com que essas necessidades são atendidas ${ }^{(5)}$.

A satisfação no contexto dos trabalhadores da área da saúde tem sido discutida em âmbito internacional ${ }^{(5-6)}$. A motivação para o trabalho é intrínseca ao sujeito que trabalha e é resultado da necessidade de se atingir desafios e objetivos. Além disso, considera-se que o envolvimento com tarefas desafiadoras, a flexibilidade do trabalho, autonomia e participação na tomada de decisões melhoram significativamente a satisfação no trabalho. No contexto dos trabalhadores da área da saúde, a conexão entre a motivação para o trabalho e a satisfação depende de vivências e percepções subjetivas ${ }^{(6)}$.

A insatisfação com o trabalho, no Brasil, é considerada como relacionada ao sofrimento e ao desgaste psíquico do trabalhador. Logo, há necessidade de investimento em estudos que investiguem as estratégias utilizadas pelos profissionais de saúde em busca da satisfação, bem como os recursos e as ações capazes de potencializá-las ${ }^{(7)}$. Aponta-se ainda a necessidade de se realizarem estudos com profissionais de saúde de distintas realidades, para auxiliar no alcance da qualidade de vida e da satisfação no trabalho ${ }^{(8)}$.

Estudo evidenciou que os residentes multiprofissionais em saúde, apesar de vivenciarem situações prazerosas em seu processo de formação, relataram vivências de sofrimento, desgaste e frustração cotidianas, os quais interferem em seu processo de trabalho e de aprendizagem $^{(9)}$. Apesar de algumas pesquisas abordarem as vivências subjetivas dos residentes multiprofissionais em saúde ${ }^{(9-10)}$, até o momento não se identificaram estudos que abordassem tais aspectos na perspectiva da satisfação e insatisfação no trabalho.

Visando o preenchimento desta lacuna, o presente artigo tem por objetivo descrever as vivências de satisfação e insatisfação de residentes multiprofissionais em saúde na perspectiva da formação.

\section{Método}

Trata-se de estudo descritivo, exploratório, com abordagem qualitativa. Optou-se por este tipo de delineamento, pois busca compreender o universo de significados, motivos, aspirações, atitudes, crenças e valores, possibilitando a descrição da vivência da realidade e de fenômenos que não podem ser reduzidos à operacionalização de variáveis ${ }^{(11)}$.

O estudo foi desenvolvido com residentes de um Programa de Residência Multiprofissional em Saúde de uma universidade pública do Sul do Brasil. Este programa subdividia-se em: Programa de Residência Multiprofissional Integrada em Gestão e Atenção Hospitalar no Sistema Público de Saúde (PRMIGAH), que abrangia as linhas crônico-degenerativo, mãe-bebê e onco-hematologia; Programa de Residência Multiprofissional Integrada em Sistema Público de Saúde (PRMISPS), abrangendo as linhas atenção básica/ saúde da família e vigilância em saúde; e Programa de Residência Multiprofissional Integrada em Saúde Mental no Sistema Público de Saúde (PRMISM) $)^{(12)}$.

Esses cursos caracterizavam-se como de pós-graduação lato sensu, com duração de dois anos, 60 horas semanais de atividades, sendo 80\% atividades práticas (48 horas semanais) e 20\% atividades teóricas e teóricas-práticas (12 horas semanais), perfazendo uma carga horária total de 5.760 horas-aula. Contemplavam os profissionais das seguintes áreas de formação: educação física, enfermagem, farmácia, fisioterapia, fonoaudiologia, nutrição, psicologia, odontologia, serviço social e terapia ocupacional ${ }^{(12)}$.

O critério de inclusão para o estudo foi ser residente multiprofissional em saúde matriculado no segundo ano de um dos Programas de Residência. Tal escolha deveu-se ao fato de esses residentes terem cursado todas as disciplinas teóricas e vivenciado diferentes situações nas atividades práticas. Foram excluídos do estudo 
os residentes que estavam em licença de qualquer natureza no período da produção de dados.

O PRMIGAH possuía 59 residentes; o PRMISPS, 16 residentes; e o PRMISM, 19 residentes matriculados. Para a seleção dos participantes, foram sorteados 5 residentes de cada um dos 3 Programas de Residência, totalizando 15 indivíduos, os quais foram convidados a tomar parte no estudo. O sorteio ocorreu de forma manual e aleatória, com base em uma lista fornecida pela Coordenação dos Programas, na qual constavam as informações: nome do residente, área específica de formação profissional, endereço eletrônico, telefone e respectiva linha em que estava matriculado. Dos 15 residentes sorteados, 9 manifestaram interesse em participar do estudo. Estes foram liberados de suas atividades pelos respectivos programas para participarem da produção de dados.

Para tanto, utilizou-se a técnica do grupo focal (GF), a qual é utilizada na pesquisa qualitativa, para que os participantes possam refletir sobre um tópico específico, recebendo estímulos apropriados para desenvolver o debate ${ }^{(13)}$. Foram realizados três encontros no mês de abril de 2013, com duração média de duas horas. O local foi uma sala localizada na universidade, à qual os programas de residência estão vinculados, em função da proximidade e facilidade de acesso para eles. A estrutura física garantiu a privacidade necessária para a pesquisa.

Além dos residentes, participaram dos encontros o pesquisador responsável pela condução dos grupos e duas observadoras, que auxiliaram no registro das falas e na identificação de cada fala com o nome do residente correspondente e também nos registros de observação da linguagem não verbal e elaboração de uma síntese das discussões, que, ao final, era lida, para que os participantes pudessem acrescentar, retificar ou contribuir com outros dados. Os encontros foram iniciados pela pergunta disparadora: Quais vivências vocês destacariam em seu processo de formação e sua relação com docentes (preceptores, tutores, professores), trabalhadores dos serviços de saúde, usuários e gestores? Os encontros foram audiogravados com o consentimento dos participantes e os dados foram transcritos em um editor de textos. Posteriormente, foram lidos exaustivamente, na busca de evidências para a melhor compreensão do conteúdo. Os dados foram submetidos à técnica da análise de conteúdo na modalidade temática, que se desenvolve em três etapas: pré-análise, exploração do material e tratamento dos resultados obtidos e interpretação ${ }^{(11)}$. Cada residente foi identificado pelas letras RM - Residente Multiprofissional, seguidas de um número cardinal (RM1, RM2, RM3, RM4, RM5...), visando preservar a confidencialidade dos dados.

O estudo seguiu as orientações da Resolução n. 466/12, do Conselho Nacional de Saúde, que regulamenta pesquisas com seres humanos. Todos os participantes assinaram o Termo de Consentimento Livre e Esclarecido (TCLE). O estudo foi aprovado no Comitê de Ética em Pesquisa da instituição sob o número do Certificado de Apresentação para Apreciação Ética (CAAE), 3934413.8.0000.5346, de 25 de março de 2013.

\section{Resultados e Discussão}

Nesta seção, é explicitada a caracterização dos participantes da pesquisa, seguida pelas categorias temáticas: Vivências de satisfação dos residentes multiprofissionais em saúde e Vivências de insatisfação dos residentes multiprofissionais em saúde.

Dos nove residentes multiprofissionais em saúde que compuseram este estudo, dois pertenciam ao PRMIGAH, três ao PRMISPS e quatro ao PRMISM. As categorias profissionais representadas foram: enfermagem, farmácia, nutrição, psicologia, serviço social e terapia ocupacional.

Em relação ao perfil sociodemográfico, observou-se o predomínio do sexo feminino $(n=7)$. Os residentes eram, majoritariamente, solteiros $(n=6)$, sem filhos $(n=7)$ e com idade média de 27,9 anos.

\section{Vivências de satisfação dos residentes multiprofissionais em saúde}

Dentre as vivências de satisfação dos residentes, destacou-se a oportunidade do trabalho multiprofissional, o qual esteve relacionado ao 
aprendizado, crescimento e qualidade das ações, conforme mostram os fragmentos de fala:

\begin{abstract}
O que me deixa feliz é poder compartilhar também com outras áreas de conbecimento e isso é fundamental. Quando temos ações multi [multiprofissionais] que dão certo, é que a gente percebe que as coisas vão se encaminhado de uma forma boa [...] (RM 2).
\end{abstract}

O grande potencial é conseguir conviver com outras áreas. A gente sai totalmente fora do núcleo [profissional] e eu acho que isso traz um aprendizado muito grande, muito rico. (RM 5).

Percebe-se que o processo de formação dos residentes ocorre por meio do trabalho em equipe interdisciplinar, com base na integração das profissões e do compartilhamento de conhecimentos e saberes. Esse processo é sentido positivamente pelos participantes, configurando vivências de satisfação. Assim, o trabalho interdisciplinar remete a uma intensa troca entre especialistas que buscam a integração das disciplinas em um mesmo projeto, veiculando as ideias de reciprocidade e de mutualidade que reforçam a produção de sentidos compartilhada ${ }^{(14)}$.

O trabalho interdisciplinar não se restringe à aglutinação de profissões. Exige articulação de equipe, por meio do reconhecimento do outro e de outro campo do conhecimento, do diálogo, da cooperação, da horizontalidade das relações e da coesão das ações em torno de objetivos convergentes $^{(15)}$. As ações em equipe, quando sedimentadas nesses pressupostos, oportunizam vivências de satisfação no cotidiano de trabalho, uma vez que os residentes não se consideram indivíduos isolados, mas profissionais que fazem parte de um corpo multiprofissional.

A competência profissional tem despontado como uma das prioridades para a gestão dos serviços de saúde, bem como para as instituições formadoras na capacitação de profissionais ${ }^{(16)}$. Tendo isso em vista, a residência multiprofissional em saúde objetiva uma formação em saúde convergente com os princípios e diretrizes do SUS, por meio da aproximação entre trabalho e formação. Objetiva mudanças no modelo técnico-assistencial, por meio da multidisciplinaridade, a qual possibilita práticas que se aproximam das concepções de integralidade e humanização da atenção em saúde ${ }^{(17)}$. Assim, a interdisciplinaridade representa uma das propostas centrais desses programas de residência, o que explica a valorização conferida pelos residentes.

A gratificação profissional ocorre por meio da realização do trabalho dos residentes, destacando-se o compromisso com os usuários e a qualidade do seu processo de formação. Isto pode ser percebido na fala:

Esse crescimento é uma coisa bem gratificante mesmo, principalmente para e pelo usuário. O que a gente faz, está fazendo agora, é tudo em prol dele depois. (RM 3).

Pesquisa evidenciou que a inserção dos residentes multiprofissionais nas equipes de saúde proporciona aumento da capacidade de resolução dos problemas de saúde dos usuários. Os residentes representam um apoio na prestação do cuidado e atuam positivamente por meio da pluralidade de conhecimentos, disposição para a discussão de casos e para a tomada de decisões articuladas entre diferentes categorias profissionais $^{(18)}$. A satisfação pessoal e profissional advém do esforço investido para o desenvolvimento do trabalho. O processo de retribuição simbólica prevê o reconhecimento por outra pessoa que, neste estudo, é o usuário. É o que evidencia a fala:

Reconbecimento do usuário é uma coisa que transmite satisfação, quando eles falam "é contigo que eu quero falar... aquilo deu certo", isso é uma coisa muito legal. (RM 6).

O reconhecimento no trabalho é nuclear na edificação da saúde e no equilíbrio psíquico do trabalhador ${ }^{(19)}$. Representa um elemento central na relação sujeito-trabalho, uma vez que ilustra a importância das relações humanas na construção da identidade pessoal. O trabalhador está constantemente sujeito ao julgamento do outro sobre si e sobre o valor do que faz em seu trabalho $^{(20)}$, e esse julgamento determina muitas de suas vivências de satisfação ou insatisfação.

Determinadas tarefas estão apoiadas em ações imateriais, isto é, não há produção de bens palpáveis. Em profissões que se destinam à prestação de serviços, por exemplo, os resultados do trabalho desempenhado são ditos "invisíveis". Nesses casos, o trabalhador necessita 
do reconhecimento da importância de seu trabalho $^{(19)}$. Isto se aplica ao trabalho em saúde, cujo foco é o cuidado ou a gestão do cuidado ao ser humano em diferentes ciclos de sua vida e em diferentes situações de saúde e doença. Portanto, o residente imerge na complexidade desse trabalho e tem, no reconhecimento do outro, dentre a pluralidade de ações que desenvolve cotidianamente, um importante elemento de satisfação. Para isso, o trabalhador mobiliza-se e engaja-se em suas atividades. Suas ações necessitam promover uma dinâmica de troca, a fim de possibilitar que os objetivos individuais e coletivos sejam alcançados. Isso converge para a fala dos residentes, ao referirem sentir satisfação quando:

Tem o reconhecimento de que a gente está fazendo a diferença, de que o nosso trabalho está valendo a pena. Isso para mim é bem gratificante. (RM 3).

Alguém liga para a gente, pede alguma coisa, sabe que a gente é referência naquela ação. [...] Isso é bem legal, faz a gente se sentir importante. (RM 9).

Estudo realizado com profissionais de saúde mostrou que concebem positivamente a atuação dos residentes multiprofissionais de saúde, uma vez que destacam seu potencial no fortalecimento das ações de saúde no cotidiano das unidades, principalmente em decorrência da interdisciplinaridade e da integralidade da atenção. O estudo evidenciou ainda que os residentes buscam relações de parceria com os membros da equipe, para a concretização de projetos ${ }^{(18)}$. Isso converge para os dados deste estudo e mostra que os residentes multiprofissionais em saúde buscam estabelecer pontes de cooperação com a equipe em busca de seu reconhecimento.

O espaço do trabalho é destacado como um local de busca pelo reconhecimento. Assim, compreende-se que a concretização do trabalho coletivo não se faz somente com base em normas, mas necessita de sentimentos de compromisso, responsabilidade e experiência ${ }^{(15)}$. Os relatos dos residentes mostram não apenas o esforço em se fazer necessários em uma equipe de saúde, como também a satisfação vivenciada quando recebem o reconhecimento desejado. Assim, compreende-se a realização profissional como a vivência de gratificação profissional e identificação com o trabalho que realizam, configurando vivências de satisfação no cotidiano dos residentes.

\section{Vivências de insatisfação dos residentes multiprofissionais em saúde}

Apesar de identificarem vivências cotidianas de satisfação, os residentes apresentaram um conjunto de situações responsáveis por sentimentos contrários. Dentre essas situações, tiveram destaque as dificuldades relacionadas à falta de comunicação na equipe de saúde, conforme mostra a fala de RM1:

\footnotetext{
Dependendo do local onde a gente está, um profissional quer que faça uma atividade, chega outro profissional e quer que a gente faça outra atividade. Isso é bumanamente impossivel.
}

Evidencia-se a insatisfação dos residentes multiprofissionais em saúde relacionada às demandas contraditórias às quais estão expostos. Isso está relacionado às formas distintas como cada equipe realiza a gestão do trabalho em saúde. Nesse sentido, estudos com residentes multiprofissionais e residentes de enfermagem afirmam que eles sentem-se sobrecarregados. Somam-se a isso as queixas frequentes quanto à falta de autonomia, sobrecarga de trabalho e sentimentos de baixa eficiência e produtividade ${ }^{(21-22)}$.

Pesquisa realizada com profissionais de saúde evidenciou que percebem fragmentações das ações de cuidado representadas pela não integração e falta de coesão na rotina de trabalho. Essa característica aponta para as dificuldades que as equipes encontram para voltar o olhar para o outro (seja o usuário, seja o colega), buscando a articulação das ações ${ }^{(15)}$. Nesse contexto, a falta de integração está relacionada às vivências de insatisfação e exige flexibilidade e criatividade no processo de trabalho em saúde, o qual é permeado pela subjetividade das ações do ser humano.

No que se refere aos conceitos teóricos que sustentam a proposta dos Programas de Residência, destacam-se dispositivos de gestão, tais como: Projeto Terapêutico Singular (PTS), Clínica Ampliada, Redes ou Linhas de Cuidados e o Matriciamento. A concretização desses dispositivos é um desafio para os residentes, devido à 
ausência de sua adoção nas práticas de trabalho cotidianas das equipes que compõem os serviços de saúde:

A gente nunca chega num consenso do que é o matriciamento. Até que ponto os residentes estão fazendo matriciamento? Que matriciamento é esse? Cada um faz de um jeito e só os residentes fazem. Como é que é isso? (RM 6).

Entende-se por matriciamento (ou apoio matricial) o sistema em que duas ou mais equipes de saúde partilham os processos de intervenção em saúde por meio da transformação da lógica tradicional dos sistemas hierárquicos de saúde (encaminhamentos, referências, contrarreferências protocolos e centros de regulação). O matriciamento objetiva o estabelecimento de articulações horizontais entre os serviços, com integração dos componentes e seus saberes nos diferentes níveis assistenciais ${ }^{(23)}$. Os residentes multiprofissionais em saúde percebem dificuldades para operar tais dispositivos na sua formação e encontram entraves para consolidá-los junto à equipe dos serviços de saúde nos quais estão inseridos.

Por sua própria natureza, o trabalho em saúde não se realiza isoladamente, pois nenhum núcleo profissional sozinho consegue atender às necessidades de saúde dos usuários. Neste sentido, o trabalho pressupõe a articulação dos residentes, da gestão e dos trabalhadores dos serviços de saúde que atuam no contexto da residência, dada a complexidade e multiplicidade das necessidades em saúde.

Outra vivência de insatisfação para os residentes multiprofissionais em saúde refere-se à falta de tempo para a realização de atividades profissionais e pessoais devido à extensa carga horária dos programas, conforme mostram as falas:

Em que borário a gente estuda? Em que borário a gente produz? Em que borário a gente manda [para uma revista científica] o artigo? (RM 2).

Ninguém trabalha 60 boras por muito tempo e consegue dar conta do tipo de trabalbo que a gente tem que fazer, com o estudo junto, mais o processo de trabalbo. É difícil. (RM 5).

Os Programas de Residência superam a carga horária mínima obrigatória dos cursos de especialização lato sensu tradicionais, que, conforme a Resolução n. 1, de 8 de junho de 2007, do Conselho Nacional de Educação (CNE) e Conselho Nacional de Saúde (CNS), devem conter carga horária mínima de 360 horas integrando o ensino, o serviço e a pesquisa, e exigem apresentação da Monografia de Conclusão de Curso $^{(24)}$. Assim, a carga horária prática é a principal característica que distingue a residência dos demais cursos de formação profissional, uma vez que se caracteriza por ser uma formação em serviço.

As sensações de desgaste e sobrecarga são elementos geradores de sofrimento no processo de formação dos residentes, uma vez que, muitas vezes, eles não conseguem atender a todas as demandas que lhes são atribuídas ${ }^{(9)}$. Os dados mostram que as limitações impostas pela extensa carga horária causam insatisfação nos residentes, uma vez que não conseguem concretizar todos os planos e projetos idealizados.

Os residentes multiprofissionais em saúde também referem que as atividades teóricas são proveitosas, mas também são restritas, devido à falta de articulação da teoria com a prática vivenciada por eles, conforme evidencia a fala:

Eu acho que poderia ter tido disciplinas que fossem ao encontro das necessidades que a gente evidenciava enquanto prática porque, sinceramente, teve algumas que não me acrescentaram em muita coisa e algumas que eu vi que acabaram faltando. (RM 3).

Este dado vai ao encontro de estudo recente, realizado com residentes multiprofissionais em saúde, no qual identificou-se distanciamento entre a teoria discutida nas disciplinas e a realidade experienciada no cotidiano da prática ${ }^{(10)}$. Portanto, pode-se considerar que esta vivência de insatisfação seja comum a outras realidades no âmbito das residências multiprofissionais em saúde.

No que tange à formação, espera-se que os residentes multiprofissionais em saúde tornem-se capazes de refletir criticamente acerca de sua prática profissional e de atuar como articuladores na resolução de problemas nos diferentes cenários de assistência do SUS, para a criação de alternativas inovadoras, que visem à consolidação das redes ${ }^{(10)}$. Para tanto, é fundamental 
que a formação no âmbito da residência esteja sedimentada nas demandas cotidianas da prática. A realidade dos serviços de saúde deve fornecer as perguntas e inquietações disparadoras de reflexão e, portanto, deve estar permanentemente presente no processo de formação teórica.

Outro elemento de insatisfação para os residentes multiprofissionais em saúde é o descontentamento com a antecipação de atividades e o agendamento de atividades que não haviam sido acordadas anteriormente:

Falta cumprimento das coisas que são pactuadas. Porque nós acordamos que vai ter uma reunião daqui há quinze dias e de repente a gente recebe um e-mail no meio da tarde ou no sábado de manhã... E a gente tem uma programação da nossa vida [...] (RM 2).

Nos programas de Residência em Enfermagem, algumas manifestações dos residentes relacionadas às condições de trabalho referem-se à falta de tempo para o lazer, o que pode favorecer o esgotamento físico mental/emocional ${ }^{(21)}$. Esse contexto pode ser aproximado ao do estudo, pois ambos mostram exigências do trabalho que se sobrepõem, muitas vezes, à vontade e aos planos pessoais do residente.

Os dados de ambas as categorias ilustram importantes elementos de satisfação e insatisfação no trabalho e na formação dos residentes, uma vez que apontam para vivências de frustração e impotência. Sabe-se que o trabalhador alimenta desejos em torno de sua satisfação pessoal e profissional e deseja não ser visto como um executante passivo de atividades ${ }^{(25)}$. Assim, aspectos subjetivos são fundamentais na constituição da identidade enquanto profissional e na construção de vivências de saúde no processo de trabalho e formação.

Portanto, descrever vivências de satisfação e insatisfação é importante, para que se percebam as lacunas e fragilidades existentes nos programas de residência e se pensem estratégias para superá-las. Assim, poder-se-á estruturar modelos de residências multiprofissionais em saúde que proporcionem experiências plenas, humanas, edificantes e transformadoras aos residentes. Os impactos desses modelos dar-se-ão na qualidade da assistência prestada por esses profissionais, na estruturação de serviços de saúde integrados e resolutivos e, em especial, na saúde psíquica desses trabalhadores.

Diante disso, destaca-se a participação da enfermagem nesse desafio, dada a sua representatividade e atuação nos programas de residência multiprofissional em saúde. O enfermeiro é um profissional engajado em diferentes ações convergentes com as propostas dos programas de residência multiprofissional em saúde, como ações de educação continuada e permanente, formação em saúde e extensão universitária. Essas ferramentas podem auxiliar no amadurecimento dos programas de residências por meio da formação de pontes, parcerias e ações conjuntas.

Os dados desta pesquisa foram produzidos pelo grupo focal, que se mostrou um instrumento apropriado para o objetivo do estudo. Contudo, a não articulação com outros instrumentos consiste em uma limitação, dada a restrição de fontes de evidências. Pesquisas que associem diferentes instrumentos de produção de dados, referenciais teóricos e metodológicos podem ser realizadas, visando ao aprofundamento das questões aqui discutidas. Assim, aponta-se para a necessidade de novos estudos que contribuam com diferentes ferramentas e perspectivas para o fortalecimento da temática.

\section{Conclusão}

O estudo mostrou que as principais vivências de satisfação no processo de formação e trabalho dos residentes estiveram relacionadas ao compartilhamento de conhecimentos e saberes de campo e núcleo profissional, bem como à gratificação profissional do usuário e dos serviços pelo trabalho que executam. Já as vivências de insatisfação relacionaram-se à falta de comunicação e descontinuidade de algumas ações, sobrecarga de trabalho, extensa carga horária, dificuldade de articulação da teoria com a prática nas disciplinas e a antecipação de atividades que não haviam sido acordadas anteriormente.

Os resultados encontrados mostram que, apesar de o processo de formação dos residentes conferir-lhes satisfação, os participantes 
vivenciavam sentimentos opostos. Identificar as vivências de satisfação e insatisfação no cotidiano dos residentes pode auxiliar os programas a considerar mudanças em seus modelos, convergindo para o reconhecimento da experiência do residente. Nesse contexto, a enfermagem pode contribuir, por meio da atuação de seu núcleo profissional nos programas de residência. Almeja-se que os resultados deste estudo contribuam para a sensibilização das instituições formadoras, fortalecendo o planejamento de ações na formação em saúde, especialmente no âmbito das residências multiprofissionais.

\section{Colaborações:}

1. concepção, projeto, análise e interpretação dos dados: Marcelo Nunes da Silva Fernandes, Carmem Lúcia Colomé Beck e Teresinha Heck Weiller;

2. redação do artigo, revisão crítica relevante do conteúdo intelectual: Alexa Pupiara Flores Coelho e Francine Cassol Prestes;

3. aprovação final da versão a ser publicada: Daiany Saldanha da Silveira Donaduzzi.

\section{Referências}

1. Brasil. Ministério da Saúde. Portaria n. 198/GM/ MS, de 13 de fevereiro de 2004. Institui a Política Nacional de Educação Permanente em Saúde como estratégia do Sistema Único de Saúde para a formação e o desenvolvimento de trabalhadores para o setor e dá outras providências Brasília; 2004 [Internet]. [Cited 2015 July 20]. Available from: http://dtr2001.saude.gov.br/sas/PORTARIAS/ Port2004/GM/GM-198.htm

2. Brasil. Ministério da Saúde. Ministério da Educação e Cultura. Portaria Interministerial n. 2.117, de 3 de novembro de 2005. Institui no âmbito dos Ministérios da Saúde e da educação, a Residência Multiprofissional em Saúde e dá outras providências. Brasília; 2005. [Internet]. [Cited 2016 June 3]. Available from: http:// portal. mec.gov.br/index.php?option $=\mathrm{com}_{-}$ docman\&view $=$ download\&alias $=15207$-port -2117 03112005 \&Itemid $=30192$

3. Brasil. Ministério da Educação. Portaria Interministerial n. 45, de 12 de janeiro de 2007.
Dispõe sobre a Residência Multiprofissional em Saúde e a Residência em Área Profissional da Saúde e institui a Comissão Nacional de Residência Multiprofissional em Saúde. Brasília; 2007. [Internet]. [Cited 2015 July 2]. Available from: http://portal.saude.gov.br/portal/arquivos/pdf/ portaria_45_2007.pdf

4. Brasil. Presidência da República. Casa Civil. Lei n. 11.129, de 30 de junho de 2005. Institui o Programa Nacional de Inclusão de Jovens - ProJovem, cria o Conselho Nacional da Juventude - CNJ e a Secretaria Nacional de Juventude; altera as Leis $\mathrm{n}^{\circ} \mathrm{S}$ 10.683, de 28 de maio de 2003, e 10.429, de 24 de abril de 2002; e dá outras providências. Brasília; 2005 [Internet]. [Cited 2012 Sept 13]. Available from: http://www.planalto.gov.br/ccivil_03/_Ato20042006/2005/Lei/L11129.htm

5. Al Magbali MA. Factors that influence nurses' job satisfaction: a literature review. Nurs Manag [Internet]. 2015 [cited 2016 May 10];22(2):30-7. Available from: http://journals.rcni.com/doi/ pdfplus/10.7748/nm.22.2.30.e1297

6. Djordjević D, Petrović D, Vuković D, Mihailović D, Dimić A. Motivation and job satisfaction of health workers in a specialized health institution in Serbia. Vojnosanit Pregl [Internet]. 2015 [cited 2016 May 10];72(8):714-21. Available from: http://www. doiserbia.nb.rs/img/doi/0042-8450/2015/004284501500055D.pdf

7. Trindade LL, Bordignon M, Ferraz L, Amestoy SC. Professional satisfaction and quality of care in oncology: the vision of health professional. J res fundam care online [Internet] 2015 [cited 2016 May 15];7(2):2383-92. Available from: http://www.seer. unirio.br/index.php/cuidadofundamental/article/ view/3895/pdf_1550

8. Bordignon M, Ferraz L, Beck CLC, Amestoy SC, Trindade LL. (In)satisfação dos profissionais de saúde no trabalho em oncologia. Rev Rene [Internet]. 2015 [cited 2015 May 15];16(3):398-406. Available from: http://www.periodicos.ufc.br/ index.php/rene/article/view/2811/2180

9. Fernandes MNS, Beck CLC, Weiller TH, Viero V, Freitas PH, Prestes FC. Suffering and pleasure in the process of forming multidisciplinary health residentes. Rev Gaúcha Enferm [Internet]. 2015 [cited 2016 June 5];36(4):90-7. Available from: http://www.scielo.br/pdf/rgenf/v36n4/1983-1447rgenf-36-04-00090.pdf

10. Silva CT, Terra MG, Kruse MHL, Camponogara S, Xavier MS. Multi-professional residency as an 
intercessor for continuing education in health. Texto Contexto Enferm [Internet]. 2016 [cited 2016 June 12];25(1):e2760014. Available from: http://www.scielo.br/pdf/tce/v25n1/en_01040707-tce-25-01-2760014.pdf

11. Bardin L. Análise de conteúdo. Lisboa: Edições 70; 2011.

12. Universidade Federal de Santa Maria. Projeto do Programa de Residência Multiprofissional Integrada em Sistema Público de Saúde. Santa Maria [Internet]; 2009 [cited 2012 Aug 30]. Available from: http://www.ufsm.br/prpgp/

13. Donaduzzi DSS, Beck CLC, Weiller TH, Fernandes MNS, Viero V. Grupo focal y análisis de contenido en investigación cualitativa. Index Enferm. 2015;24(1-2):71-5.

14. Maia DB, Sousa ETG, Gama RM, Lima JC, Rocha PCF, Sassaki Y. Atuação interdisciplinar na Atenção Básica de Saúde: a inserção da Residência Multiprofissional. Sau \& Transf Soc [Internet]. 2013 [cited 2015 June 24];4(1):103-10. Available from: http://www.redalyc.org/pdf/2653/265325753017. pdf

15. Silva EM, Moreira MCN. Health team: negotiations and limits of autonomy, belonging and the acknowledgement of others. Ciênc Saúde Coletiva [Internet]. 2015 [cited 2016 June 22]; 20(10):303342. Available from: http://www.scielo.br/pdf/csc/ v20n10/en_1413-8123-csc-20-10-3033.pdf

16. Leal LA, Camelo SHH, Soares MI, Santos FC, Correa R, Chaves LDP. Competências profissionais para enfermeiros: a visão de discentes de graduação em enfermagem. Rev baiana enferm [Internet]. 2016 [cited 2016 Oct 18];30(3):1-12. Available from: http://www.portalseer.ufba.br/index.php/ enfermagem/article/view/16380/pdf_67

17. Bezerra TCA, Falcão MLP, Goes PSA, Felisberto E. Avaliação de programas de formação profissional em saúde: construção e validação de indicadores. Trab Educ Saúde [Internet]. 2016 [cited 2016 June 30];14(2):445-72. Available from: http://www. scielo.br/pdf/tes/v14n2/1678-1007-tes-19817746-sip00111.pdf

18. Domingos CM, Nunes EFPA, Carvalho BG. Potencialidades da residência multiprofissional em Saúde da Família: o olhar do trabalhador de saúde. Interface (Botucatu) [Internet]. 2015 [cited 2015 July 3];19(55):1221-32. Available from: http://www.scielo.br/pdf/icse/v19n55/1807-5762icse-1807-576220140643.pdf

19. Dejours C. Subjetividade, trabalho e ação. Prod [Internet]. 2004 [cited 2016 July 3];14(3):27-34. Available from: http://www.scielo.br/pdf/prod/ v14n3/v14n3a03.pdf

20. Bendassolli PF. Reconhecimento no trabalho: perspectivas e questões contemporâneas. Psicol Estud [Internet]. 2012 [cited 2016 July 8];17(1):3746. Available from: http://www.scielo.br/pdf/pe/ v17n1/v17n1a04.pdf

21. Franco GP, Barros ALBL, Nogueira-Martins LA, Zeitoun SS. Burnout in nursing residents. Rev Esc Enferm USP [Internet]. 2011 [cited 2016 July 14];45(1):12-8. Available from: http://www.scielo. br/pdf/reeusp/v45n1/en_02.pdf

22. Guido LA, Goulart CT, Silva RM, Lopes LFD, Ferreira EM. Stress and Burnout among multidisciplinary residents. Rev Latino-Am Enfermagem [Internet]. 2012 [cited 2016 July 15];20(6):1064-71. Available from: http://www.scielo.br/pdf/rlae/v20n6/08.pdf

23. Chiaverini DH, organizador. Guia prático de matriciamento em saúde mental. Brasília, DF: Ministério da Saúde; Centro de Estudo e Pesquisa em Saúde Coletiva; 2011. [cited 2016 Oct 18]. Available from: http://repositorio.caminhosdocuidado. org/bitstream/handle/581/1/Guia\%20 pr\%C3\%A1tico\%20de\%20matriciamento\%20 em\%20sa\%C3\%BAde\%20mental.pdf

24. Brasil. Conselho Nacional de Educação. Resolução n. 1, de 8 de junho de 2007. Estabelece normas para o funcionamento de cursos de pós-graduação lato sensu, em nível de especialização [Internet]. Brasília; 2007. [cited 2016 July 29]. Available from: http://portal.mec.gov.br/index. php?option=com_content\&id $=12899$

25. Dejours C. A banalização da injustiça social. 7a ed. Rio de Janeiro: Fundação Getúlio Vargas; 2006.

Recebido: 27 de outubro de 2016 Aprovado: 25 de agosto de 2017 Publicado: 26 de outubro de 2017 